MOUSQUER, C.J. et al. Metabolismo visceral e eficiência do uso da energia por animais taurinos e zebuínos. PUBVET, Londrina, V. 8, N. 5, Ed. 254, Art. 1684, Março, 2014.

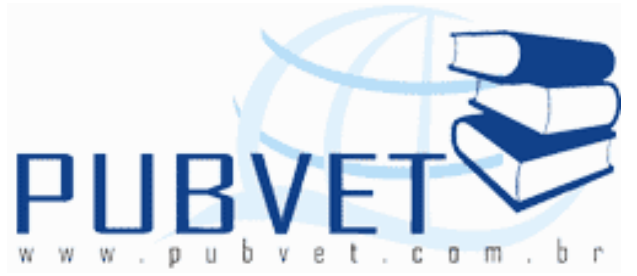

PUBVET, Publicações em Medicina Veterinária e Zootecnia.

\title{
Metabolismo visceral e eficiência do uso da energia por animais taurinos e zebuínos
}

\section{Claudio Jonasson Mousquer ${ }^{1 *}$, Eduardo Henrique Bevitori Kling de Moraes $^{2}$, Geferson Antonio Fernandes ${ }^{3}$, Alvair Hoffmann ${ }^{4}$, Tiago Adriano Simioni ${ }^{4}$, Wanderson José Rodrigues de Castro ${ }^{1}$, Amorésio Souza Silva Filho ${ }^{1}$, Fabíola Francisca Dias Fernandes ${ }^{5}$}

${ }^{1}$ Mestrandos em Ciência Animal da UFMT, Campus de Cuiabá-MT

${ }^{2}$ Zootecnia/ICAA/UFMT/Campus de Sinop, Bolsista do CNPq, Pesquisador do INCT/CNPq - Ciência Animal

${ }^{3}$ Zootecnista, UFMT, campus de Sinop-MT

${ }^{4}$ Mestrandos em Zootecnia da UFMT, Campus de Sinop-MT

${ }^{5}$ Médica Veterinária, UFMT, campus de Sinop-MT

* Autor para correspondência: cjm@zootecnista.com.br

\section{RESUMO}

A relação entre consumo de energia metabolizável, energia retida e produção de calor, juntamente com a separação das funções de mantença e produção, constituem a base para a discussão dos fatores que afetam as exigências de energia e sua eficiência de utilização nos bovinos. O conhecimento da eficiência energética de diferentes espécies de bovinos e suas exigências de energia para o ganho de peso e para a mantença é importante para se obter produtividade máxima com custo mínimo. A avaliação do tamanho relativo dos órgãos é de 
MOUSQUER, C.J. et al. Metabolismo visceral e eficiência do uso da energia por animais taurinos e zebuínos. PUBVET, Londrina, V. 8, N. 5, Ed. 254, Art. 1684, Março, 2014.

extrema importância, devido possuir influência direta no rendimento de carcaça e sobre a exigência de energia para mantença. As partes nãointegrantes da carcaça variam, em peso, de acordo com a raça, o estádio de maturidade e o nível nutricional. O tamanho relativo dos órgãos internos é de suma importância, pois possui influência direta sobre o rendimento da carcaça e exigência de energia para mantença. O metabolismo energético tem influência direta dos fatores extrínsecos e intrínsecos ao animal, entre eles, idade, peso, raça, composição corporal, condição sexual, potencial de produção, condições ambientais, atividade e nível de alimentação. O conhecimento da eficiência de utilização da energia metabolizável da dieta para os diferentes processos biológicos é necessário para a determinação das exigências de energia metabolizável (a partir das exigências líquidas). Assim, a geração de informação e o volume de publicações em comparação dos Bos tauros e Bos índicus deve aumentar a fim de possuir normas nutricionais e diferença nas de partições de energia mais consolidadas, pois ainda há muito conflito na literatura até mesmo dentro de uma mesma raça.

Palavras-chave: Bovinos; exigências de mantença; órgãos

\section{Visceral metabolism and efficiency of energy use in animals taurine and zebuine}

\section{ABSTRACT}

The relationship between energy intake, retained energy and heat production, along with the separation of maintenance and production, form the basis for discussion of the factors that affect energy requirements and efficiency of use in cattle. The knowledge of the energy efficiency of different species of cattle and their energy requirements for weight gain and for maintenance is important to obtain maximum productivity with minimum cost. The evaluation of the relative size of the organs is of utmost importance due to have a direct influence on carcass yield and the energy requirement for maintenance. The parties do not integrate carcass vary in weight according to race, stage of 
MOUSQUER, C.J. et al. Metabolismo visceral e eficiência do uso da energia por animais taurinos e zebuínos. PUBVET, Londrina, V. 8, N. 5, Ed. 254, Art. 1684, Março, 2014.

maturity and nutritional level. The relative size of the internal organs is of paramount importance as it has a direct influence on carcass yield and energy requirement for maintenance. The energy metabolism has direct influence of extrinsic and intrinsic to the animal, including age, weight, race, body composition, sexual condition, production potential, environmental conditions, activity and feeding level. Knowledge of the efficiency of utilization of metabolizable energy of the diet for different biological processes is necessary for the determination of metabolizable energy requirements (from the net requirements). Thus, the generation of information and the volume of publications on comparison of Bos tauros and Bos indicus must increase in order to own nutritional standards and differences in the partition of energy more statements because there is much conflict in the literature even within the same race.

Keywords: Cattle, maintenance requirements, organs

\section{INTRODUÇÃO}

Tomando por base o crescimento da bovinocultura de corte no Brasil, que vem assumindo forte liderança na economia nacional e também no mercado mundial de carnes, o Brasil possui o maior rebanho bovino comercial do mundo com mais de 200 milhões de cabeças (IBGE, 2011) e maior exportador de carne bovina, sendo, cada vez mais em destaque não só em números, como também em eficiência nas formulações e utilização dos recursos em coprodutos que são empregados na alimentação de ruminantes, potencializando o sistema com esse tipo de alimento que em determinada região e época se torna uma das principais estratégias para alavancar cada vês mais a pecuária de corte e leite nos trópicos, sendo considerada atrativa e lucrativa em meio a grandes outras atividades agropecuárias dentro do cenário nacional.

Com uma produtividade média de pouco mais de duas arrobas de carne/ha/ano (Paulino, 2006; Goulart, 2006), a pecuária de corte vem 
MOUSQUER, C.J. et al. Metabolismo visceral e eficiência do uso da energia por animais taurinos e zebuínos. PUBVET, Londrina, V. 8, N. 5, Ed. 254, Art. 1684, Março, 2014.

passando por nova fase de transformações profundas, sendo empregado o uso de biotecnologias de produção, possibilitando incrementos não só em produtividade, mas também em maior rentabilidade ao produtor agropecuário.

O crescimento rápido é uma característica desejável na bovinocultura de corte, pois os animais que têm maior capacidade de crescimento precisam de menor período de tempo para atingir a puberdade e assim a idade de abate, consequentemente maior giro de capital, potencializando o sistema como um todo.

A competitividade brasileira na produção de carne advinda das fases de cria, recria e engorda, deve-se, a pecuária extensiva praticadas principalmente com as raças zebuínas adaptadas as condições de clima e solo do Brasil e, á constante melhoria dos índices de produtividade devido ao melhoramento genético, avanços na nutrição e das tecnologias de produção.

A maior parte do rebanho brasileiro é constituída de zebuínos e, dentre os zebuínos, destacando principalmente a raça Nelore com mais de 100 milhões de animais (Sainz et al., 2004), apresentando boa adaptação às condições de ambiente tropical, ambiente esse, destacado por Marcondes et al. (2009) como clima quente e úmido, presença de endo e ectoparasitas e oferta de forragem irregular devido a sazonalidade das pastagens que ocorre durante 0 ano. Porém sendo enfatizado na raça, produtividade inferior a outros genótipos principalmente em função de um manejo nutricional deficiente (Putrino, 2002), que ainda ocorre na grande maioria dos sistemas de produção.

Logo a raça Nelore, sendo amplamente difundida pelo país, ainda sofre problemas como o manejo nutricional deficiente, que acaba prejudicando o desempenho produtivo e reprodutivo. Assim, estudos baseados nas respostas da raça aos diferentes tipos de alimentos utilizados para bovinos contribuem para aumentar o conhecimento sobre as exigências nutricionais do Nelore em ambiente tropical (Putrino, 2006).

Os taurinos são animais menos adaptados ao clima tropical porem, animais de melhores acabamento e precocidade. A busca por uma raça que apresentasse altos índices de produção associados à adaptação às duras 
MOUSQUER, C.J. et al. Metabolismo visceral e eficiência do uso da energia por animais taurinos e zebuínos. PUBVET, Londrina, V. 8, N. 5, Ed. 254, Art. 1684, Março, 2014.

condições de clima e meio ambiente de regiões tropicais e subtropicais levaram pesquisadores do mundo todo iniciarem trabalhos de cruzamentos controlados, envolvendo raças européias e zebuínas (Maciel, 2000).

O balanceamento de rações e suplementos para determinados níveis de desempenho, assim como a estimativa do desempenho a partir de dietas balanceadas, requerem o conhecimento das exigências nutricionais para as diferentes funções, para os diferentes níveis de desempenho (Boin, 1995) e categoria animal.

Como destaca Valadares Filho et al. (2005), diversos países já estabeleceram as normas nutricionais de seus rebanhos de corte, levando em consideração as peculiaridades de suas realidades: França em 1978 (INRA, 1978), Inglaterra em 1965 (ARC, 1965), Reino Unido em 1980 (ARC, 1980), Estados Unidos em 1984 (NRC, 1984), Austrália em 1990 (CSIRO, 1990) e África do Sul em 1993 (AFRC, 1993). O sistema americano (NRC) já passou inclusive por duas revisões e atualizações (NRC, 1996 e 2000), quando novos avanços obtidos no estudo das exigências nutricionais dos animais foram incorporados.

O Brasil, no entanto, dispõe de sua tabela de exigências nutricionais o BRCORTE, 2010 (Valadares Filho et al., 2010), porém muito pouco utilizado pelos pecuaristas nacionais, pela baixa confiabilidade de seus dados, motivo esse muitas vezes relacionado a uma amostra pequena que originou os resultados da tabela, sendo portanto, o sistema mais empregado nas formulações brasileira de dietas, ainda o sistema americano (NRC), onde a base de dados são de bovinos da raça Angus (Bos taurus) e, no Brasil alguns autores (Ripamonte, 2002; Putrino, 2002) destacam que, aproximadamente $80 \%$ de sua população bovina são de origem Bos indicus.

Portanto, determinar as exigências nutricionais do nosso rebanho significa oferecer a sociedade brasileira tecnologia de produção gerada sob nossas condições, notadamente distintas daquelas presentes em países de clima temperado (Marcondes et al., 2010). 
MOUSQUER, C.J. et al. Metabolismo visceral e eficiência do uso da energia por animais taurinos e zebuínos. PUBVET, Londrina, V. 8, N. 5, Ed. 254, Art. 1684, Março, 2014.

A energia utilizada pelos animais é obtida dos alimentos através de processos digestivos e metabólicos, considerados energeticamente ineficientes, devido a perdas que ocorrem em cada um dos diversos estágios de assimilação de nutrientes (Marcondes et al., 2010).

\section{REVISÃO BIBLIOGRÁFICA}

\section{Características das raças zebuínas (bos indicus) e taurinas (bos taurus)}

Em países abrangidos por regiões tropicais, a produção de carne é baseada, principalmente, em raças bovinas zebuínas (Bos indicus), e seus cruzamentos com Bos taurus (Yokoo et al., 2010; Chizzotti et al., 2008), sendo a produção de carne bovina caracterizada por sistemas de produção baseados em pastagens recobertas por forrageiras tropicais e em animais predominantemente da raça Nelore, se concretizando a de maior ocorrência (Valadares Filho et al., 2005).

Devido à sua melhor adaptação ao clima tropical, as raças zebuínas se difundiram bastante no Brasil, embora algumas raças taurinas, como a Holandesa, também tenham grande participação na pecuária nacional devido às suas peculiaridades principalmente na produção leiteira. Dentre as raças bovinas atualmente existentes no país, o Nelore, Gir e Guzerá representam a maioria das raças de origem zebuína e o Brahman, Tabapuã e Indubrasil a maioria das raças compostas por cruzamento de raças zebuínas.

Os animais Bos indicus se expandiu aos poucos pelo país, entrando primeiro pelos estados do Rio de Janeiro e Bahia e em seguida no triângulo Mineiro, sendo o Estado de São Paulo o último a aderir à criação de zebuínos (Putrino, 2002). A última importação ocorreu em 1962, trazendo touros que contribuíram para a formação da base do rebanho brasileiro atual. (Viacava et al., 2000). 
MOUSQUER, C.J. et al. Metabolismo visceral e eficiência do uso da energia por animais taurinos e zebuínos. PUBVET, Londrina, V. 8, N. 5, Ed. 254, Art. 1684, Março, 2014.

Os animais de origem zebuína, são bastante adaptados às condições tropicais, se expandiu por todo território brasileiro, alcançando uma alta proporção em termos de rebanho. Segundo Pineda (2000), esta grande expansão se deve às características da raça, em termos de fertilidade, rusticidade, adaptabilidade ao ambiente tropical e adequação a um sistema de produção extensivo.

De acordo com Barbosa (1999), o uso da seleção em gado zebu proporciona resultados comparáveis à estratégia de cruzamentos para produção de novilhos precoces quanto ao peso, idade de abate e espessura de gordura.

Frisch e Vecoe (1977); Taylor et al. (1968) tem demonstrado que o Bos taurus indicus tem menores necessidades de mantença que o Bos taurus taurus, o que the daria vantagens em momentos de escassez de alimento, por exemplo, durante a estação seca.

Estas informações sugerem menor capacidade de ingestão de alimentos nos animais zebuínos em relação aos taurinos e mestiços (Jorge et al., 1999). Embora taurinos e zebuínos tenham originado de um ancestral comum, eles evoluíram em ambientes bastante distintos e, portanto, na atualidade divergem em muitos aspectos, que em muitas vezes os tornam distintos.

Porem de via de regra, os taurinos são animais europeus que evoluíram em regiões de clima temperado, enquanto os zebuínos são animais indianos que evoluíram em regiões de clima tropical. É por isso, que as raças zebuínas (por exemplo, Nelore, Gir, Brahman, Guzerá e Tabapuã) se adaptam muito melhor ao clima brasileiro que as raças taurinas (por exemplo, Angus, Simental, Limousin, Holandês e Jersey).

Em bovinos, pode-se separar três grandes grupos de acordo com a precocidade e tamanho de frame size: as raças precoces ou de pequeno porte (Bos taurus Britânicos como o Angus e Hereford), as raças médias (Bos indicus como o Nelore e Brahman) e as raças tardias ou de grande porte (Bos taurus continentais como a Charolesa, Chianina e Simental). Para a mesma idade cronológica e regime alimentar, as raças precoces ou menor frame size 
MOUSQUER, C.J. et al. Metabolismo visceral e eficiência do uso da energia por animais taurinos e zebuínos. PUBVET, Londrina, V. 8, N. 5, Ed. 254, Art. 1684, Março, 2014.

apresentam menor peso e maior deposição de tecido adiposo na carcaça. As diferenças raciais também determinam diferenças na proporção músculo:osso. Os bovinos que são selecionados para musculosidade, superam as outras na relação músculo:osso.

\section{Metabolismo Visceral}

O desempenho dos ruminantes é altamente dependente do consumo de matéria orgânica (MO) digestível e da eficiência como os nutrientes absorvidos são utilizados pelos animais. Porem, a regulação da disponibilidade de nutrientes para os tecidos periféricos é afetada pelo metabolismo visceral. $\mathrm{O}$ sistema visceral é representado pelos tecidos drenados pela veia porta (trato gastrintestinal, gordura mesentérica, pâncreas e baço) mais o fígado (Kozloski et al., 2009).

Nos animais ruminantes, a glicose sanguínea como tal é limitada, pois no rúmen os carboidratos são metabolizados até AGV e se alguma parte do amido alcançar o intestino delgado, a degradação enzimática via amilase pancreática não ira contribuir significativamente com aumento da oferta de glicose, pois a amilase dos ruminantes é relativamente pouco eficiente. Portanto, a rota mais importante para o obtenção de glicose tecidual, é via transformação do propionato, produzido na fermentação ruminal, em glicose, através da gliconeogênese. E essa glicose é utilizada primordialmente na sua função nobre, ou seja, a produção de ATP via ciclo de Krebs e fosforilação oxidativa, que ocorre no fígado. Costuma-se dizer que, em animais ruminantes, o fígado é o tempo todo gliconeogenético.

Alguns métodos laboratoriais e com uso de animais têm sido utilizados. Entre estes, foi desenvolvido uma metodologia que permite estudar o metabolismo visceral (que inclui as vísceras drenadas pela veia porta e fígado) in vivo, a qual envolve a utilização de animais multicateterizados e a infusão contínua na veia mesentérica de um marcador de fluxo sanguíneo,

normalmente o paraminohipurato (PAH) (Katz e Bergman, 1969) citado por Kozloski et al. (2008). 
MOUSQUER, C.J. et al. Metabolismo visceral e eficiência do uso da energia por animais taurinos e zebuínos. PUBVET, Londrina, V. 8, N. 5, Ed. 254, Art. 1684, Março, 2014.

Segundo Kozloski et al. (2009) o metabolismo e as concentrações sanguíneas dos nutrientes são resultado da interação de vários fatores associados à oferta de energia metabolizável e de cada nutriente individualmente, à condição fisiológica do animal e ao tempo após a refeição, entre outros. Assim em animais consumindo forragem, a maior parte dos carboidratos digestíveis da dieta é fermentada no rúmen a ácidos graxos voláteis e, desse modo, a absorção de glicose é nula e seu fluxo portal geralmente negativo (Huntington, 1999).

Quando compararmos somente a afim de esclarecimento, nos animais não-ruminantes, a situação já é diferente uma vez que o suprimento de glicose é normalmente mais elevado, e a conversão via propionato em grau muito menor. Isso é facilmente comprovado pelos níveis glicêmicos. Portanto, nos animais não-ruminantes, pode se observar excedente da oferta de glicose e nesse caso, a mesma irá ser depositada nos tecidos na forma de gordura (ácidos graxos de cadeia longa), sintetizada via citrato produzido na mitocôndria. Entretanto, nos animais ruminantes, essa rota está bloqueada uma vez que, a oferta de glicose é relativamente limitada. Nestes animais, a rota bioquímica para a síntese de gordura inicia-se com os ácidos graxos voláteis acético e butírico, provenientes da fermentação ruminal, tanto no tecido adiposo corporal como no da glândula mamária.

O incremento na oferta de propionato, que chegará ao fígado e transformando em glicose, para fins energéticos (produção de ATP), garantindo assim adequado suprimento de energia, já que o animal ruminante não pode basear-se com maior exclusividade na obtenção de glicose via degradação enzimática pela amilase pancreática ao nível do intestino delgado e assim, esse suprimento de ATP for adequado, evidentemente o animal não necessitará desviar outros nutrientes, dietéticos ou não, para fins de fornecimento de energia, como por exemplo, a proteína, seja ela dietética ou corporal. 
MOUSQUER, C.J. et al. Metabolismo visceral e eficiência do uso da energia por animais taurinos e zebuínos. PUBVET, Londrina, V. 8, N. 5, Ed. 254, Art. 1684, Março, 2014.

Com isso, a proteína presente na dieta poderá ser direcionada integralmente para a sua finalidade mais nobre, ou seja, a produção de massa muscular, fato esse altamente desejado para novilhos de corte.

\section{Uso da energia, metabolismo, interferência na sua eficiência e desenvolvimento dos componentes não-integrantes (visceral) da carcaça de Bos indicus e Bos taurus}

A energia é representada a partir das seguintes formas: energia bruta (EB), energia digestível (ED), energia metabolizável (EM) e energia liquida (EL). A energia bruta representa o total de energia (calor) liberada durante a completa oxidação $\left(\mathrm{CO}_{2}\right.$ e $\left.\mathrm{H}_{2} \mathrm{O}\right)$ de uma amostra em uma bomba calorimétrica, mas tem utilização limitada na nutrição animal por não indicar a disponibilidade dessa energia para o animal.

A energia digestível (ED) aparente é a diferença entre a EB consumida e a excretada nas fezes, e já a energia metabolizável EM e calculada descontandose da ED as perdas energéticas na forma de urina e gases, representando assim a fração energética que será utilizada pelo animal ou perdida como calor, que é a energia efetivamente disponível ao metabolismo do animal.

A energia líquida constitui a fração da energia ingerida disponível para o animal que pode ser utilizada para atividades de mantença (metabolismo basal, termorregulação, contração muscular, e funções associadas a síntese de proteína) (Calegare, 2004) e, produção (crescimento corporal, reprodução e produção de leite) (Aferri, 2007). Assim, cada ponto citado da partição da energia é extremamente importante de ser considerado para melhor entender as variações entre os indivíduos, principalmente na capacidade de converter o alimento em produto com eficiências distintas (Souza, 2012).

São escassas as pesquisas relacionadas à quantificação dos tecidos externos, trato gastrintestinal e órgãos internos considerando a ampla variação genética do rebanho, práticas de manejo, sexo, condição sexual e categoria animal (Kuss, 2007). Assim Kozloski et al. (2001) citaram que, o sistema visceral (fígado e vísceras drenadas pela veia porta) representa uma interface 
MOUSQUER, C.J. et al. Metabolismo visceral e eficiência do uso da energia por animais taurinos e zebuínos. PUBVET, Londrina, V. 8, N. 5, Ed. 254, Art. 1684, Março, 2014.

entre a dieta e o animal, e atua como o principal local de regulação dos nutrientes que são utilizados para a manutenção, crescimento, lactação, reprodução e atividades físicas dos animais.

As taxas de crescimento dos órgãos e dos tecidos são influenciadas por fatores como tamanho do corpo, nível nutricional e hormônios. No entanto, as diferenças existentes principalmente quanto ao tamanho dos órgãos internos entre raças, podem estar associadas a diferenças nas exigências de mantença (Kuss, 2007).

O papel funcional desempenhado pelo sistema visceral (fígado e vísceras drenadas pela veia porta) tem um custo energético consideráveis e uma quantidade variável de substratos são metabolizadas por eles (Huntington e Reynolds, 1987).

Em um ruminante adulto o conjunto do tecido nervoso, coração, rins, aparelho digestivo e fígado representam menos de $10 \%$ da massa corporal, recebem aproximadamente $55 \%$ do rendimento cardíaco (Ferrell, 1993) e, gastam cerca de $50 \%$ do total de energia para mantença (Ferreira et al., 2000; Caton e Dhuyvetter, 1997), onde também podendo ser incluso a glândula mamária, como um tecido de grande atividade metabólica, de maior importância a bovinocultura leiteira.

Por outro lado, o tecido muscular, que constitui cerca de $41 \%$ da massa corporal, consome apenas $23 \%$ do total da energia requerida para mantença (Véras et al., 2001). Isso ocorre porque certos tecidos associados com a digestão, como o trato gastrintestinal e o fígado, têm maior "turnover" protéico do que o músculo esquelético (Owens et al., 1993).

Quando sofre alterações no metabolismo dos tecidos viscerais, pode alterar as proporções e as quantidades absolutas de metabolismo que os tornam disponíveis para os tecidos periféricos e, consequentemente, podem influenciar o metabolismo do organismo inteiro (Kozloski et al., 2001). Alem disso a eficiência com que os ruminantes utilizam a energia dos alimentos é baixa e é dependente da quantidade de perdas nas fezes e produção de calor (Moraes, 2006). 
MOUSQUER, C.J. et al. Metabolismo visceral e eficiência do uso da energia por animais taurinos e zebuínos. PUBVET, Londrina, V. 8, N. 5, Ed. 254, Art. 1684, Março, 2014.

Segundo Caton e Dhuyvetter (1997), em ruminantes adultos, a maior parte da energia utilizada para mantença $(50 \%)$ é consumida pelas vísceras. Sendo o coração, fígado e trato gastrintestinal, entre os tecidos de maior atividade metabólica nos animais, e grandes utilizadores de energia. Posada et al. (2011) destaca que com a idade, um animal que atinge a maturidade apresenta declínio na proporção dos órgãos viscerais, especialmente o fígado (tabela 1 ) e o trato digestivo (tabela 2 ), resultando em uma redução na exigência de energia para mantença.

Assim em decorrência da menor exigência de energia para mantença, proporcionalmente ao peso corporal, mais energia pode ser gasta para o crescimento da carcaça, particularmente a deposição de gordura (Putrino et al., 2006). Logo, animais mais velhos tendem a terem maiores quantidades de energia depositada em regiões mais específicas como; subcutânea, inter e intramuscular.

Kuss et al. (2007) observou que, a medida que aumentou ou elevou-se o peso de abate $(465 \mathrm{~kg}, 507 \mathrm{~kg}$ e $566 \mathrm{~kg}$ ) de vacas de descarte Charolês $\mathrm{x}$ Nelore, ouve uma redução em \% do corpo vazio (PCVZ) do fígado, baço, pulmão, concentrações de fluído de sangue e conjunto de órgãos vitais (tabela $1)$.

Kuss et al. (2007) ainda destaca que uma das suposição para o T507 ter relações maiores de órgãos, seria o efeito do ganho de peso: ao longo do processo de terminação, os animais apresentaram ganho de peso médio diário de 1,26; 1,59 e 1,28 kg (T465, T507 e T566, respectivamente), ou seja, a maior velocidade de ganho de peso no T507 exigiu maior demanda de oxigenação (pulmões) e capacidade de armazenamento de sangue (baço), a fim de acompanhar a produção dos tecidos muscular e adiposo. Como também pode ser evidenciado nas proporções do TGI (tabela 2). De acordo com ARC (1980) o conteúdo do TGI pode ser influenciado pelo peso corporal, pela raça do animal, pelo estado fisiológico e pelo tipo de alimentação. 
MOUSQUER, C.J. et al. Metabolismo visceral e eficiência do uso da energia por animais taurinos e zebuínos. PUBVET, Londrina, V. 8, N. 5, Ed. 254, Art. 1684, Março, 2014.

Tabela 1 - Pesos de corpo vazio, coração, fígado, pulmões, rins, baço, conjunto dos órgãos vitais coração + fígado + pulmões + rins + baço) (COV) de vacas de descarte abatidas com diferentes pesos.

\begin{tabular}{|c|c|c|c|}
\hline \multirow{3}{*}{ Característica } & \multicolumn{3}{|c|}{ Peso de Abate } \\
\hline & \multicolumn{3}{|c|}{ \% do corpo vazio } \\
\hline & T465 & T507 & T566 \\
\hline Sangue & $3,66 \pm 0,14 a$ & $3,61 \pm 0,14 a$ & $3,14 \pm 0,14 b$ \\
\hline Coração & $0,44 \pm 0,02$ & $0,42 \pm 0,02$ & $0,38 \pm 0,02$ \\
\hline Fígado* & $1,46 \pm 0,05 a b$ & $1,51 \pm 0,05 a$ & $1,38 \pm 0,05 b$ \\
\hline Pulmão** & $1,26 \pm 0,06 b$ & $1,45 \pm 0,06 a$ & $1,14 \pm 0,06 b$ \\
\hline Rins & $0,22 \pm 0,02$ & $0,22 \pm 0,02$ & $0,18 \pm 0,02$ \\
\hline Baço* & $0,27 \pm 0,03 b$ & $0,36 \pm 0,03 a$ & $0,20 \pm 0,03 c$ \\
\hline $\operatorname{cov} * *$ & $3,65 \pm 0,08 b$ & $3,95 \pm 0,08 a$ & $3,28 \pm 0,08 c$ \\
\hline \multirow{2}{*}{\multicolumn{4}{|c|}{$\begin{array}{l}\text { a, b, c: médias na mesma linha diferem } * *(P<0,05) \text { ou } *(P<0,10) \text { pelo teste } t \text {. Adaptado de } \\
\text { Kuss et al. (2007). } \\
\text { Tabela } 2 \text { - Peso de rúmen-retículo, abomaso, omaso, estomago (rúmen- } \\
\text { retículo }+ \text { abomaso }+ \text { omaso), intestinos (delgado }+ \text { grosso) e } \\
\text { trato gastrintestinal (estômago }+ \text { intestinos) (TGI) de vacas de } \\
\text { descarte abatidas com diferentes pesos. }\end{array}$}} \\
\hline & & & \\
\hline \multirow[t]{2}{*}{ Característica } & \multicolumn{3}{|c|}{ Peso de Abate \% do Corpo Vazio } \\
\hline & T465 & T507 & T566 \\
\hline Rúmen-Retículo** & $3,62 \pm 0,12 a$ & $3,81 \pm 0,12 a$ & $2,26 \pm 0,12 b$ \\
\hline Abomaso* & $0,87 \pm 0,10 a$ & $0,91 \pm 0,10 a$ & $0,55 \pm 0,10 b$ \\
\hline Omaso** & $1,34 \pm 0,17 b$ & $1,88 \pm 0,17 a$ & $1,70 \pm 0,17 a b$ \\
\hline Estomago** & $5,83 \pm 0,26 b$ & $6,60 \pm 0,26 a$ & $4,51 \pm 0,26 c$ \\
\hline Intestinos* & $4,41 \pm 0,27 b$ & $5,14 \pm 0,27 a$ & $4,53 \pm 0,27 a b$ \\
\hline TGI $* *$ & $10,24 \pm 0,34 b$ & $11,74 \pm 0,34 a$ & $9,04 \pm 0,34 c$ \\
\hline
\end{tabular}

$a$, b, c: médias na mesma linha diferem $* *(P<0,05)$ ou $*(P<0,10)$ pelo teste $t$. Adaptado de Kuss et al. (2007). 
MOUSQUER, C.J. et al. Metabolismo visceral e eficiência do uso da energia por animais taurinos e zebuínos. PUBVET, Londrina, V. 8, N. 5, Ed. 254, Art. 1684, Março, 2014.

Logo, Moraes (2006) ao analisar exigências liquidas de energia e conteúdo de gordura em diferentes pesos de animais anelorados, pode observar que, quando se aumenta o PV do animal, também há um aumento do incremento nos conteúdos de gordura e nas exigência de energia no ganho de PCVZ em animais anelorados (tabela 3 ).

Tabela 3 - Exigências líquidas de energia (Mcal/kg GPCVZ) e conteúdo de gordura no GPCVZ ( $\mathrm{g} / \mathrm{kg}$ GPCVZ) de bovinos anelorados sob pastejo.

\begin{tabular}{lcc}
\hline $\begin{array}{l}\text { Peso vivo } \\
\text { (kg) }\end{array}$ & $\begin{array}{c}\text { Exigência de energia } \\
\text { (Mcal/ kg GPCVZ) }\end{array}$ & $\begin{array}{c}\text { Conteúdo de gordura } \\
\text { (g/ kg GPCVZ) }\end{array}$ \\
\hline $\mathbf{2 5 0}$ & 3,2 & 213,62 \\
$\mathbf{3 0 0}$ & 3,56 & 289,01 \\
$\mathbf{3 5 0}$ & 3,9 & 373,17 \\
$\mathbf{4 0 0}$ & 4,21 & 465,64 \\
\hline
\end{tabular}

$\mathrm{PCVZ}=\mathrm{PV} * 0,8877$. Moraes (2006); Moraes et al. (2009)

Próximos a asses resultados, Paulino et al. (1999b) trabalhando com diferentes grupos zebuínos encontrou para exigências liquidas de energia (Mcal/kgPCV) em animais de 300, 350 e $400 \mathrm{~kg}$ de PV, valores de 3,38; 3,87 e 4,34 respectivamente.

Ao analisarmos as afirmações de Perón et al. (1993) que zebuínos apresentam depósito de gordura periférica mais pronunciado em detrimento ao depósito de gordura interna e, também as citações de alguns autores (Kuss et al., 2007; Fernandes et al., 2005; Jorge et al., 1999) de que também apresentam menor tamanho de órgãos internos pode-se inferir que, em relação aos taurinos, as exigências de energia para mantença de animais zebuínos sejam inferiores.

Moraes et al. (2009) encontrou valores de $64,00 \mathrm{kcal} / \mathrm{PV}^{0,75} / \mathrm{dia}$ de exigência de energia líquida de mantença (ELm) em bovinos anelorados em regime de pastejo, valor esse $8,20 \%$ inferior do valor de $69,30 \mathrm{kcal} / \mathrm{PV}^{0,75} / \mathrm{dia}$ recomendado pelo NRC (2000), onde basicamente é um dos mais utilizado para formulação das dietas de bovinos no Brasil, 12,3 \% superior do valor de 
MOUSQUER, C.J. et al. Metabolismo visceral e eficiência do uso da energia por animais taurinos e zebuínos. PUBVET, Londrina, V. 8, N. 5, Ed. 254, Art. 1684, Março, 2014.

$57,00 \mathrm{kcal} / \mathrm{PV}^{0,75} /$ dia encontrado por Fontes et al. (2005) que, trabalhou com bovinos $3 / 4$ Holandes-Gir castrados em pastagens de capim-elefante (Pennisetum purpureum, Shum.) e maior também pelo encontrado por Paulino et al. (1999), com valor de $60,38 \mathrm{kcal} / \mathrm{PCVZ}^{0,75} / \mathrm{dia}$ de ELm em animais zebuínos criados em confinamento.

Já Pires et al. (1993) trabalhando com 3 grupos genéticos Nelore, 1/2 Nelore/Marchidiana e $1 / 2$ Nelore/Limousin, obteve valores de 34,17 $\mathrm{kcal} / \mathrm{PCVZ}^{0,75}, 67,92 \mathrm{kcal} / \mathrm{PCVZ}^{0,75}$ e $68,03 \mathrm{kcal} / \mathrm{PCVZ}^{0,75}$, respectivamente para os devidos grupamento genético, o que mais a frente o autor ressalva que possivelmente isso ocorreu por, animais zebuínos terem menores atividades metabólicas, devido há menores tamanhos de órgãos viscerais e a medida que se aumenta a consanguinidade de animais taurinos, acaba aumentando na exigência de mantença.

Fontes et al. (2005) argumentaram que a maior exigência de energia de mantença para os taurinos e mestiços pode ser também, devido há um maior conteúdo de proteína corporal (massa muscular), resultando em maior reciclagem de proteína ou reciclagem da uréia no fígado.

Essas variações de exigências energéticas para mantença podem ser explicadas, pelas diferenças entre raças, condição fisiológica e corporal, aspectos nutricionais, sexo, genótipo e mais (Solis et al., 1988). Conhecendose as exigências líquidas e levando-se em consideração os fatores de eficiência de utilização da energia do alimento para mantença e ganho, obtêm-se as exigências dietéticas (Ferreira et al., 1998).

Pesquisas tem demonstrado haver diferenças no peso do trato gastrintestinal e órgãos internos de animais zebuínos em comparação a taurinos e mestiços. Lunt et al. (1986) utilizando novilhos Angus, Brahman e Angus x Brahman, alimentados com dietas à base de forragem ou grãos, verificaram que a raça, o ganho de peso diário médio e a dieta influenciaram no peso da massa dos órgãos vitais. Novilhos Angus apresentaram maiores pesos de coração, fígado e pulmões, ao passo que os novilhos alimentados com forragem tiveram maior massa de coração e fígado em relação aos 
MOUSQUER, C.J. et al. Metabolismo visceral e eficiência do uso da energia por animais taurinos e zebuínos. PUBVET, Londrina, V. 8, N. 5, Ed. 254, Art. 1684, Março, 2014.

alimentados com dieta à base de grãos. Ferrel e Jenkins (1998) também reportaram maiores valores de coração, fígado, pulmão, rins e baço para animais Angus e Hereford em relação ao Brahman.

Susenbeth et al. (1998) citado por Kozloski et al. (2001) verificaram que a exigência de energia para alimentação e ruminação é alto e diferente entre a dieta fornecida. Quando fornecido volumoso de baixa qualidade em bovinos, aproximadamente $30 \%$ da energia metabolizável da alimentação foi usada para fornecer a energia exigida para a alimentação e ruminação. Por sua vez, quando fornecido um volumoso de alta qualidade, apenas $10 \%$ da energia metabolizável foi usada para estas funções fisiológicas.

Solis et al. (1988) utilizando vacas de descarte Angus, Brahman, Hereford, Holstein e Jersey, verificaram menor requerimento de mantença para vacas Brahman, reflexo da menor atividade metabólica dos órgãos e menor quantidade de gordura interna. Assim como é destacado por Kuss et al. (2007) que, as diferenças no tamanho dos órgãos internos, entre raças, podem estar associadas às exigências de mantença.

Menor massa de trato gastrintestinal, órgãos (coração, fígado, rins, baço e pulmões) e gordura interna foram encontrados em animais pertencentes a grupos genéticos de corte (Nelore e 1/2 Nelore-Chianina) em comparação a animais de grupos raciais leiteiros (1/2 Nelore-Holandês, 1/2 Holandês-Gir e 3/4 Holandês-Gir) Perón et al. (1993).

O NRC (2000), destaca que a Exigência Líquida de mantença ELm pode variar em até $40 \%$ dependendo da raça bovina, assim animais zebuínos em fase de crescimento, obtém requerimentos de energia de mantença, por unidade de tamanho metabólito, aproximadamente $10 \%$ inferiores que a dos taurinos. Já a CSIRO (1990), recomenda níveis de ELm para zebuínos 20\% menores que os níveis dos animais taurinos.

Para exigência em energia de zebuínos, foram encontrados por Paulino et al. (2004) em novilhos anelorados valores diários de exigência mantença em $68,69 \mathrm{kcal} / \mathrm{PV}^{0,75}$, bem abaixo dos valores propostos por Lofgreen e Garret 
MOUSQUER, C.J. et al. Metabolismo visceral e eficiência do uso da energia por animais taurinos e zebuínos. PUBVET, Londrina, V. 8, N. 5, Ed. 254, Art. 1684, Março, 2014.

(1968) onde, em comparação ao trabalho de Paulino, superestimam em 77,0 $\mathrm{kcal} / \mathrm{PV}^{0,75}$.

O metabolismo visceral acaba alterando o padrão e a quantidade de nutrientes que são disponíveis para os tecidos periféricos, mas também há gasto de uma parte significativa da energia consumida por todo o organismo do animal. O aumento da ingestão dos alimentos ou de energia, aumenta a massa destes órgãos viscerais em relação à massa total do corpo (Burrin et al., 1990) e a atividade metabólica destes tecidos (Reynolds, 1995).

Ferrell et al. (1976), avaliando as exigências de novilhas em diferentes estágios de gestação, observaram que os órgãos internos de novilhas de raças leiteiras (Jersey e Holandês) são, proporcionalmente, maiores que os de novilhas de corte (Hereford). Assim, concluíram, que o total de energia para mantença exigido pelo tecido muscular é menor que o da energia exigida pelos órgãos internos, o que acaba explicando as maiores exigências (em parte) para mantença de novilhas leiteiras.

Em raças com aptidão leiteira, os maiores depósitos de gordura estão em maiores proporções nos tecidos que não fazem parte da carcaça (órgãos e vísceras), diferentemente das tradicionais raças de corte, em que os depósitos periféricos são mais pronunciados, ocasionado menor exigência para mantença destes últimos (Owens et al., 1995), já que as maiores taxas metabólicas estão no fígado e juntamente ao TGI .

Backes et al. (2010) avaliando o tamanho relativo dos órgão internos e TGI de bovinos Indubrasil e Mestiços leiteiro, pode relatar que em termos de gordura interna obteve-se, em valores absolutos, maior deposição em animais mestiços leiteiros. Para gordura mesentérica, houve diferença significativa $(P<0,05)$, sendo maior para os mestiços leiteiros (tabela 4$)$. O que comprova que animais mestiços leiteiros, em fase de engorda, depositam mais gordura internamente do que os animais indubrasil e consequentemente maiores demandas energéticas. 
MOUSQUER, C.J. et al. Metabolismo visceral e eficiência do uso da energia por animais taurinos e zebuínos. PUBVET, Londrina, V. 8, N. 5, Ed. 254, Art. 1684, Março, 2014.

Tabela 4 - Médias dos pesos de rúmen-retículo, omaso, abomaso, conjunto rúmen-retículo-omaso-abomaso (Estômago), mesentério e da gordura interna em porcentagem do peso do corpo vazio ( $\%$ PCVZ), e coeficiente de variação (CV), em percentagem, em animais mestiço leiteiro e indubrasil, em fase de engorda.

\begin{tabular}{lccc}
\hline \multirow{2}{*}{ Itens } & Mestiços leiteiros & Indubrasil & \multirow{2}{*}{ CV\% } \\
\cline { 2 - 3 } & $\%$ PCVZ & \% PCVZ & \\
\hline Rúmen-retículo & $1,714^{\mathrm{a}}$ & $1,828^{\mathrm{a}}$ & 6,14 \\
Omaso & $0,745^{\mathrm{a}}$ & $0,630^{\mathrm{a}}$ & 9,82 \\
Abomaso & $0,261^{\mathrm{a}}$ & $0,300^{\mathrm{a}}$ & 6,56 \\
Estomago & $2,720^{\mathrm{a}}$ & $3,159^{\mathrm{a}}$ & 9,3 \\
Mesentério & $4,061^{\mathrm{a}}$ & $2,982^{\mathrm{b}}$ & 12,22 \\
Gordura interna & $1,659^{\mathrm{a}}$ & $1,521^{\mathrm{a}}$ & 7,39 \\
\hline
\end{tabular}

Médias, nas linhas, seguidas de letras distintas são diferentes $(P<0,05)$ pelo teste Tukey. Adaptado de Backes et al. (2010)

De acordo com Gesualdi Jr. et al. (2001), os estudos sobre o desenvolvimento e enchimento do trato gastrintestinal (TGI) e o peso dos órgãos internos de bovinos de corte são escassos na literatura brasileira. Isso se deve possivelmente, ao fato de estas variáveis não fazerem parte da carcaça comercial (Ribeiro et al., 2001).

Animais Bos taurus continentais, são animais de frame size maiores quando comparado aos Bos indicus e Bos taurus britânicos e tendem a ter a deposição de gordura mais tardia, porem Goulart (2006) avaliando diferentes grupos genéticos (GG) (Nelore, Aberdeen Angus x Nelore, Canchim x Nelore e Simental $x$ Nelore) obteve em seu trabalho usando animais na terminação em confinamento com a mesma idade, acabamento de gordura em animais $1 / 2$ Simental/Nelore semelhantes a animais $1 / 2$ Canchim/Nelore e Nelore (tabela 5), destacando que animais de consanguinidade Bos taurus continentais podem responder em acabamento de gordura semelhantemente a animais de frame size menores como o caso do Nelore na mesma idade de abate. 
MOUSQUER, C.J. et al. Metabolismo visceral e eficiência do uso da energia por animais taurinos e zebuínos. PUBVET, Londrina, V. 8, N. 5, Ed. 254, Art. 1684, Março, 2014.

Tabela 5 - Características de carcaça de quatro grupos genéticos em terminação

\begin{tabular}{|c|c|c|c|c|c|}
\hline \multirow{2}{*}{ Variáveis } & \multicolumn{4}{|c|}{ Grupos Genéticos $^{1}$} & \multirow{2}{*}{$\begin{array}{l}\text { Erro } \\
\text { Padrão }\end{array}$} \\
\hline & AN & CN & NE & SN & \\
\hline Idade de Abate & $759^{a}$ & $743^{a}$ & $765^{a}$ & $749^{a}$ & 8,3 \\
\hline $\begin{array}{l}\text { Peso Inicial de Carcaça } \\
\text { Quente (kg) }\end{array}$ & $180^{a}$ & $167^{\mathrm{b}}$ & $159^{b}$ & $169^{a b}$ & 4,1 \\
\hline $\begin{array}{l}\text { Peso Final de Carcaça } \\
\text { Quente (kg) }\end{array}$ & $273^{a}$ & $249^{b}$ & $249^{b}$ & $256^{a b}$ & 7,6 \\
\hline Ganho de Carcaça (kg/dia) & $0,920^{a}$ & $0,810^{b}$ & $0,891^{a b}$ & $0,860^{a b}$ & 0,030 \\
\hline $\begin{array}{l}\text { Rendimento de Carcaça no } \\
\text { Ganho ( } \% \text { do ganho em } \\
\text { jejum) }\end{array}$ & $54^{b}$ & $54^{b}$ & $58^{a}$ & $54^{b}$ & 0,03 \\
\hline $\begin{array}{l}\text { Espessura de Gordura } \\
\text { Inicial }(\mathbf{m m})\end{array}$ & $0,2^{a}$ & $0,2^{a}$ & $0,2^{a}$ & $0,0^{a}$ & 0,2 \\
\hline $\begin{array}{l}\text { Espessura de Gordura } \\
\text { Final (mm) }\end{array}$ & $8,8^{a}$ & $4,4^{b}$ & $4,4^{b}$ & $4,0^{b}$ & 0,7 \\
\hline
\end{tabular}

Goulart (2006) quando avaliou o rendimento de carcaça (tabela 5) nos diferente grupos genéticos, mesmo obtendo menor tamanho corporal em animais Nelore, obteve melhor rendimento de carcaça $(P<0,05)$, o autor cita que esse menor rendimento de carcaça se deu possivelmente ao menor tamanho do TGI e uma menor deposição de gordura pélvica renal (tabela 6) o que fez que animais de outros grupamentos genético apresentassem essa inferioridade.

Tabela 6 - Peso dos órgãos viscerais, em porcentagem de peso em jejum (Pj) dos quatro grupos genéticos ao final do confinamento.

\begin{tabular}{|c|c|c|c|c|c|}
\hline \multirow[t]{2}{*}{ Variáveis } & \multicolumn{4}{|c|}{ Grupamento Genético ${ }^{1}$} & \multirow{2}{*}{$\begin{array}{c}\text { Erro } \\
\text { Padrão }\end{array}$} \\
\hline & AN & $\mathbf{C N}$ & NE & SN & \\
\hline Peso de Fígado (\% do Pj) & $1,40^{\mathrm{a}}$ & $1,38^{\mathrm{a}}$ & $1,35^{\mathrm{a}}$ & $1,37^{\mathrm{a}}$ & 0,04 \\
\hline Peso de Rins ( \% do Pj) & $0,20^{a}$ & $0,18^{\mathrm{a}}$ & $0,18^{a}$ & $0,19^{a}$ & 0,01 \\
\hline Peso de Coração ( \% do Pj) & $0,30^{\mathrm{a}}$ & $0,29^{a}$ & $0,26^{\mathrm{b}}$ & $0,31^{a}$ & 0,02 \\
\hline Peso de GRP (\% do Pj) & $1,60^{b}$ & $1,40^{\mathrm{bc}}$ & $1,20^{c}$ & $1,86^{\mathrm{a}}$ & 0,31 \\
\hline
\end{tabular}


MOUSQUER, C.J. et al. Metabolismo visceral e eficiência do uso da energia por animais taurinos e zebuínos. PUBVET, Londrina, V. 8, N. 5, Ed. 254, Art. 1684, Março, 2014.

Como pode ser observado na tabela 6 que, animais do grupamento genético $1 / 2$ Simental/Nelore pelo seu tipo biológico de serem animais mais tardios quando comparados aos demais grupos genéticos, tem uma deposição de gordura pélvica renal mais acentuada que os demais, com isso uma deposição de gordura na carcaça mais tardia. Isso só comprova que animais Bos taurus tem uma maior deposição de gordura pélvica renal que animais os Bos indicus o que leva a conclusão de que há um gasto energético maior e muito por isso menores rendimentos de carcaça, uma vez que gordura interna é retirada nos processos de evisceração.

Mesmo não obtendo diferença estatística nas proporções de alguns órgãos dos diferentes grupos genéticos nesse trabalho de Goulart (2006), quando visualizamos os valores absolutos desses órgãos, as proporções do Nelore foi menor em todos os órgãos contabilizados, concretizando no melhor rendimento de carcaça e comprovando uma superioridade nessa raça, o que também pode ser visto por Putrino (2002) que avaliou a diferença no rendimento de carcaça de dois GG, animais Nelore e Brangus em diferentes níveis de dieta a raça Nelore foi superior ao rendimento de carcaça.

Para todos os níveis de dietas Putrino (2002) encontrou maiores \% de extrato etéreo na carcaça de Brangus em comparação ao Nelore, recebendo as mesmas quantidades de concentrado na dieta (20, 40, 60 e 80\%). Para animais Brangus o autor destaca a composição de corpo vazio em porcentagem (\%) de extrato etéreo valores de 21,$08 ; 21,43 ; 24,74$ e $23,33 \%$ e, para raça Nelore 17,$11 ; 18,01 ; 17,05$ e 16,73 respectivamente. Já os valores de proteínas o inverso do visto para extrato etéreo, sendo maiores para animais Nelore $(18,93 ; 18,70 ; 18,82$ e 18,89) e inferiores ao Brangus $(16,42 ; 16,34 ; 15,56$ e 15,89$)$.

O autor conclui que a raça Brangus são mais exigentes em energia, pela elevada deposição de gordura na carcaça em todos os níveis de dietas, que foram maiores que a raça Nelore, comprovando ainda mais que animais taurinos ou de consanguinidade taurina, tem uma maior tendência de 
MOUSQUER, C.J. et al. Metabolismo visceral e eficiência do uso da energia por animais taurinos e zebuínos. PUBVET, Londrina, V. 8, N. 5, Ed. 254, Art. 1684, Março, 2014.

deposição de gordura visceral, necessitando de maiores demandas energéticas para suprir suas necessidades metabólicas e também para o ganho.

\section{CONCLUSÃO}

A medida do fluxo de metabólitos pelo sistema visceral utilizando animais multicateterizados pode constituir-se em uma ferramenta adicional útil para avaliar o metabolismo dos ruminantes.

O metabolismo energético esta influenciado por fatores intrínsecos e extrínsecos ao animal. O conhecimento destes fatores representa uma oportunidade para encaminhar propostas de pesquisa dirigidas para determinação de exigências de energia mais precisas de Bos taurus e Bos indicus. Foi possível observar que animais taurinos e suas consanguinidades, possuem maiores deposição de gordura na carcaça e com isso maiores demandas energéticas. Mais informações são necessária para realmente termos com maior acurácia e eficiência, a utilização da energia de animais zebuínos e taurinos de diversas categorias.

\section{Agradecimento}

Ao Programa de Pós-graduação em Ciência Animal (PPGCA) da Universidade Federal de Mato Grosso, juntamente com a Faculdade de Agronomia, Medicina Veterinária e Zootecnia (FAMEVZ) do campus universitário de Cuiabá, sem a qual não seria possível a realização desse trabalho.

\section{Referências Bibliográficas}

AFERRI, G. Exigências de energia e proteína e composição do ganho em peso compensatório de novilhos Nelore por meio do indicador óxido de deutério. Pirassununga-SP: Universidade de São Paulo: USP, 2007. 90p. (Tese de Doutorado).

AGRICULTURAL AND FOOD RESEARCH COUNCIL - AFRC. Energy and protein requirements of ruminants. Wallingford: Commonwealth Agricultural Bureaux international, 1993.159p.

AGRICULTURAL RESEARCH COUNCIL - ARC. The nutrient requirements of farm livestock. No 2 Ruminants. London: Commonwealth Agricultural Bureaux, 1965. 264p. 
AGRICULTURAL RESEARCH COUNCIL - ARC. The nutrient requirements of ruminant livestock. London: Commonwealth Agricultural Bureaux, 1980. 351p.

BACKES, A. A.; PAULINO, M. F.; ALVES, D. D. et al. Tamanho relativo dos órgãos internos e do trato gastrintestinal de bovinos indubrasil e mestiços leiteiros em fase de engorda. Ciência Rural, v.40, n.5, p.1160-1165, 2010.

BARBOSA, P F. Raças e estratégias de cruzamento para produção de novilhos precoces. In: I Simpósio de produção de gado de corte. Viçosa, 1999. Anais... Viçosa-MG. p.1-18. 1999.

BOIN, C. Alguns dados sobre exigências de energia e de proteína de zebuínos. In: SIMPÓSIO INTERNACIONAL SOBRE EXIGÊNCIAS NUTRICIONAIS DE RUMINANTES, 1, 1995, Viçosa. Anais...Viçosa: Universidade Federal de Viçosa. 1995. p.457-466.

BURRIN, D. G.; FERREL, C. L.; Britton, R. A. et al. Nível de nutrição e tamanho do órgão visceral e atividade metabólica em ovelhas. British Journal of Nutrition , v.64, p.439-448, 1990.

CALEGARE, L. N. P. Exigências e Eficiência Energética de Vacas de Corte Nelore e de Cruzamentos Bos taurus x Nelore. Piracicaba-SP: ESALQ/USP, 2004.79p. (Dissertação de Mestrado).

CATON, J. S.; DUHYVETTER, D. V. Influence of energy supplementation on grazing ruminants: Requirements and responses. Journal of Animal Science. v.75, p.533- 542, 1997.

CHIZZOTTI, M. L.; TEDESCHI, L. O.; VALADARES FILHO, S. C. A. Meta-analysis of energy and protein requirements for maintenance and growth of Nellore cattle. Journal of Animal Science, v.86, n.7, p.1588-1597, 2008.

COMMONWEALTH SCIENTIFIC AND INDUSTRIAL RESEARCH ORGANIZATION - CSIRO. Feeding Standards for Australian Livestock. Ruminants. Melbourne.: 1990.

FERNANDES, H. J.; PAULINO, M. F.; MARTINS, R. G. R. et al. Crescimento de componentes corporais de três grupos genéticos nas fase de recria e terminação. Revista Brasileira de Zootecnia, v.34, p.288-296, 2005.

FERREIRA, M. A.; VALADARES FILHO, S. C.; MUNIZ, E. B. et al. Características das Carcaças, Biometria do Trato Gastrintestinal, Tamanho dos Órgãos Internos e Conteúdo Gastrintestinal de Bovinos F1 Simental $x$ Nelore Alimentados com Dietas contendo Vários Níveis de Concentrado. Revista Brasileira de Zootecnia, v.29, n.4, p.1174-1182, 2000.

FERREIRA, M. A.; VALADARES FILHO, S. C.; SILVA, J. F. C. et al. Eficiência de Utilização da Energia Metabolizável para Ganho de Peso e Exigências de Energia Metabolizável e Nutrientes Digestíveis Totais de Bovinos F1 Simental x Nelore. Revista Brasileira de Zootecnia, v.28, n.2, p.368-373, 1998.

FERRELL, C.L., GARRET, W.N., HINMAN, N. Estimation of body composition in pregnant and non pregnant heifers. Journal of Animal Science, v.42, n.5, p.1158-1166, 1976.

FERRELL, C. L.; JENKINS, T. G. Body composition and energy utilization by steers of diverse genotypes fed a high-concentrate diet during the finishing period: II. Angus, Boran, Brahman, Hereford, and Tuli sires. Journal of Animal Science, v.76, p.647-657, 1998.

FERRELL, C. L. Metabolismo de la Energía. En: Church DC, editor. El Rumiante: Fisiología Digestiva y Nutrición. Zaragoza: ACRIBIA; 1993. p.283-303. 
FONTES, C. A.; OLIVEIRA, R. C.; ERBESDOBLER, E. et al. Uso do Abate Comparativo na Determinação da Exigência de Energia de Mantença de Gado de Corte Pastejando CapimElefante: Descrição da Metodologia e dos Resultados. Revista Brasileira de Zootecnia, v.34, p.1721-1729, 2005.

FRISCH, S. E.; VERCOE, J. E. Food intake, eating rate, weight gains, metabolic rate and efficiency of feed utilization in Bos taurus and Bos indicus crossbred cattle. Anim. Prod., Edimburgh, UK, v. 25, n. 3, p. 343-358, dez., 1977.

GESUALDI JR., A.; VELOSO, C.M.; PAULINO, M.F. et al. Níveis de concentrado na dieta de bovinos F1 Limousin $x$ Nelore: peso de órgãos internos e trato digestivo. Revista Brasileira de Zootecnia, v.30, n.6, p.1866-1871, 2001.

GOULART, R. S. Desempenho, características de carcaça, composição corporal e exigências líquidas de crescimento de bovinos Nelore e três cruzamentos Bos taurus x Nelore. Piracicaba-SP: ESALQ/USP, 2006. 74p. (Dissertação de Mestrado).

HUNTINGTON, G.B., REYNOLDS, C.K. Oxygen consumption and metabolite flux of bovine portal-drained viscera and liver. Journal of Nutrition, v.117, p.1167-1173, 1987.

HUNTINGTON, G.B. Sources of variation in splanchnic blood flow in steers. Journal of Animal Science, v.77, p.3031-3036, 1999.

IBGE. 2010 - Instituto Brasileiro de Geografia e Estatística. Disponível em: < www.sidra.ibge.gov.br >. Acessado em: 24/05/2013.

I'INSTITUT NATIONAL DE LA RECHERCHE AGRONOMIQUE - INRA. Alimentation des Ruminants. INRA Publications. Versailles.: 1978. 232p.

JORGE, A. M.; FONTES, C. A. A.; PAULINO, M. F. et al. Tamanho Relativo dos Órgãos Internos de Zebuínos sob Alimentação Restrita e Ad libitum. Revista Brasileira de Zootecnia, v.28, n.2, p.374-380, 1999.

KATZ, M. L.; BERGMAN, E. N. Simultaneous measurements of hepatic and portal venous blood flow in the sheep and dog. American Journal of Physiology, v.216, p.946-952, 1969.

KOZLOSKI, G. V.; LIMA, L. D.; CHIESA, A. P. R. et al. Fluxo portal e visceral líquido de metabólitos em ovinos alimentados com feno de capim-arroz cortado com diferentes idades de rebrota. Revista Brasileira de Zootecnia, v.38, n.6, p.1114-1120, 2009.

KOZLOSKI, G. V.; LIMA, L. D.; FIORENTINI, G. et al. Implantação e avaliação do método de multicateterização em ovinos. Ciência Rural, v.38, n.1, p.258-261, 2008.

KOZLOSKI, G. V.; ROCHA, J. B. T.; CIOCCA, M. L. S. Visceral Metabolism and Efficiency of Energy use by Ruminants. Ciência Rural, Santa Maria, v.31, n.5, p.909-915, 2001.

KUSS, F. Componentes não - Integrantes da Carcaça e Características da Carcaça e da Carne de Novilhos Inteiros ou Castrados, Abatidos aos 16 ou 26 Meses de Idade. Porto Alegre-RS: UFRGS, 2007. 132p. (Tese de Doutorado).

KUSS, F.; RESTLE, J.; BRONDANI, I. L. et al. Órgãos vitais e trato gastrintestinal de vacas de descarte mestiças Charolês $x$ Nelore abatidas com pesos distintos. Revista Brasileira de Zootecnia, v.36, n2, p.421-429, 2007. 
LOFGREEN, G. P.; GARRETT, W. N. A system for expressing net energy requirements and feed values for growing and finishing beef cattle. Journal of Animal Science, v.27, n.3, p.793806, 1968.

LUNT, D. K.; BYERS, F. M.; GREENE, L.W. et al. Effects of breed, diet, and growth rate on vital organ mass in growing and finishing beef steers. Journal of Animal Science. v.63, n.1, p.7071, 1986.

MACIEL, R. A. Introdução à raça Brangus e seu uso no Brasil Central. Pecuária de Corte, ano XII, n.105, 12/2000; 01/2001.

MARCONDES, M. I.; VALADARES FILHO, S. C.; PAULINO, P. V. R. et al. Exigências nutricionais de proteína, energia e macrominerais de bovinos Nelore de três classes sexuais. Revista Brasileira de Zootecnia, v.38, n.8, p1587-1596, 2009.

MARCONDES, M. I.; CHIZZOTTI, M. L.; VALADARES FILHO, S. C. et al. Exigências Nutricionais de Energia para Bovinos de Corte. BR-CORTE, 2010. p. 85-112.

MORAES, E. H. B. K. Desempenho e exigências de energia, proteína e minerais de bovinos de corte em pastejo, submetidos a diferentes estratégias de suplementação. Viçosa-MG: Universidade Federal de Viçosa, 2006. 133p. Tese (Doutorado em Zootecnia) Programa de Pós Graduação em Zootecnia, Universidade Federal de Viçosa, Viçosa, 2006.

MORAES, E. H. B. K.; PAULINO, M. F.; MORAES, K. A. K. et al. Exigências de energia de bovinos de corte em pastejo. Revista Brasileira de Zootecnia, v.38, n.5, p.933-940, 2009.

NATIONAL RESEARCH COUNCIL - NRC. Nutrient requirements of beef cattle. 6 ed. National Academy Press, Washington, D.C.: 1984. 90p.

NATIONAL RESEARCH COUNCIL - NRC. Nutrient requirements of beef cattle. 7 rev. ed. National Academy Press, Washington, D.C.: 2000. 242p.

OWENS, F. N.; DUBESKI, P.; HANSON, C. F. Factors that alter the growth and development of ruminants. Journal of Animal Science, v.71, p.3138-3150, 1993

OWENS, F.N., GILL, D.R., SECRIST, D.S. et al. Review of some aspects of growth and development of feedlot cattle. Journal of Animal Science, v.73, n.12, p.3152-3172, 1995.

PAULINO, M. F.; FONTES, C. A. A.; JORGE, A. M. et al. Exigências de energia para mantença de bovinos zebuínos não-castrados em confinamento. Revista Brasileira de Zootecnia, v.28, n.3, p.621-626. 1999.

PAULINO, M. F.; FONTES, C. A. A.; JORGE, A. M. et al. Composição Corporal e Exigências de Energia e Proteína para Ganho de Peso de Bovinos de Quatro Raças Zebuínas. Revista Brasileira de Zootecnia, v.28, n.3, p.627-633, 1999b.

PAULINO, P. V. R.; COSTA, M. A. L.; VALADARES FILHO, S. C. et al. Exigências nutricionais de zebuínos: Energia. Revista Brasileira de Zootecnia, v.33, n.3, p.781- 791, 2004.

PAULINO, P. V. R. Desempenho, Composição corporal e Exigências Nutricionais de Bovinos Nelore de Diferentes Classes Sexuais. Viçosa-MG: UFV, 2006. 183p. (Tese de Doutorado). 
PERON, A. J.; FONTES, C. A. A.; LANA, D. P. et al. Tamanho de órgãos internos e distribuição da gordura corporal em novilhos de cinco grupos genéticos, submetidos à alimentação restrita e ad libitum. Revista da Sociedade Brasileira de Zootecnia. v.22, n.5, p.813-819, 1993.

PINEDA, N. R. Influência do Nelore na produção de carne no Brasil. In: Simpósio Nelore 2000. Anais... Ribeirão Preto-SP. p. 3-13. 2000.

PIRES, C. C.; FONTES, C. A. A.; GALVÃO, J. G. et al. Exigências nutricionais de bovinos de corte em acabamento. II exigência de energia para mantença e ganho de peso. Revis. Soc. Bras. Zootec., v.22, n.1, p.121-132, 1993

POSADA, S. L.; NOGUERA, R. R.; RODRÍGUEZ, N. M. et al. Energy requirements for beef cattle: concepts and experimental results in tropical conditions, Revista Colombiana de Ciências Pecuária, v.24, p.623-633, 2011

PUTRINO, S. M. Composição corporal, exigências de energia e proteína para ganho e composição da carne de novilhos Nelore alimentados com dietas com milho grão seco ou úmido contendo gordura não degradável no rúmen. Pirassununga-SP: USP, 2006. 100p. (Tese de Doutorado).

PUTRINO, S. M. Exigências de Proteína e Energia Líquidas para o Ganho de Peso de Tourinhos das Raças Nelore e Brangus Alimentados com Dietas com Diferentes Proporções de Concentrado. Pirassununga-SP: USP, 2002. 75p. (Dissertação de Mestrado).

PUTRINO, S. M.; LEME, P. R.; SILVA, S. et al. Exigências líquidas de proteína e energia para ganho de peso de novilhos Nelore alimentados com dietas contendo grão de milho úmido e gordura protegida. Revista Brasileira de Zootecnia, v.35, p.301-308, 2006.

REYNOLDS, C. K. Aspectos quantitativos do metabolismo hepático em ruminantes. In: VON ENGELHARDT, W., LEONHARD-Marek, S., Breves, G, et al. (Eds ) fisiologia de ruminantes: digestão, metabolismo, crescimento e reprodução. Sttutgart: Ferdinand Enke Verlag, 1995. p.351-371.

RIBEIRO, T.R.; PEREIRA, J.C.; LEÃO, M.I. et al. Tamanho de órgãos e vísceras de bezerros holandeses, para produção de vitelos, recebendo dietas com diferentes níveis de concentrado. Revista Brasileira de Zootecnia, v.30, n.6, p.2163-2168, 2001 (suplemento).

RIPAMONTE, P. Estimativa da participação do genoma de Bos taurus no rebanho Nelore. Pirassununga-SP. Faculdade de Zootecnia e Engenharia de Alimentos, 2002. 57p. Dissertação (Mestrado em Zootecnia) - Universidade de São Paulo, Faculdade de Zootecnia e Engenharia de Alimentos, 2002.

SAINZ, R. D.; BARIONI, L. G.; PAULINO, P. V. R. et al. Growth patterns of Nellore vs. British beef cattle breeds assessed using a dynamic, mechanistic model of cattle growth and composition. In: INTERNATIONAL WORKSHOP ON MODELING NUTRIENT UTILIZATION IN FARM ANIMALS, 6., 2004., Wageningen. Proceedings... Wageningen: Wageningen University, 2004. p.160-170.

SOLIS, J. C.; BYERS, F. M.; SCHELLING, G. T. et al. Maintenance requirements and energetic efficiency of cows of different breed types. Journal of Animal Science. v.66, n.3, p.764-773, 1988.

SOUZA, A. R. D. L. Relações entre eficiência alimentar, características de carcaça e qualidade de carne de novilhos Nelore confinados. Piracicaba-SP: ESALQ/USP, 2002. 85p. (Tese de Doutorado), 2012 
SUSENBETH, A., MAYER, R., KOEHLER, B., et al. Energy requirement for eating in cattle. Journal of Animal Science, v.76, p.2701-2705, 1998.

TAYLOR, St. C. S.; THIESSEN, R. B.; MURRAY, J. Interbred relationship of maintenance efficiency to milk yield in cattle. Anim. Prod., Harlow, v. 43, n. 1, p.37-61, Aug. 1986.

VALADARES FILHO, S. C.; PAULINO, P. V. R.; MAGALHÃES, K. A. Exigências nutricionais de bovinos de corte no Brasil. In: CONGRESSO BRASILEIRO DE ZOOTECNIA - ZOOTEC, 10., 2005, Campo Grande. Anais... Campo Grande: Universidade Estadual do Mato Grosso do Sul, 2005. p.1-31.

VALADARES FILHO, S. C.; PAULINO, P. V. R.; MAGALHÃES, K. A. Exigências nutricionais de zebuínos e tabelas de composição de alimentos BR-CORTE. 2ed. - Viçosa: UFV, DZO, 2010, 142p.

VERAS, A. S. C.; VALADARES FILHO, S. C.; SILVA, J. F. C. et al. Eficiência de Utilização da Energia Metabolizável para Mantença e Ganho de Peso e Exigências de Energia Metabolizável e de Nutrientes Digestíveis Totais de Bovinos Nelore, Não-Castrados. Revista Brasileira de Zootecnia, v.30, n.3, p.904-910, 2001.

VIACAVA, C.; CASTANHO FILHO, E. P.; PIRES, G.; et al. Nelore - O boi ecológico que está conquistando o mundo. Ed. Peirópolis, SP. p. 39-44. 2000.

YOKOO, M. J.; LOBO, R. B.; ARAUJO, F. R. C. et al. Genetic associations between carcass traits measured by real-time ultrasound and scrotal circumference and growth traits in Nellore cattle. Journal of Animal Science, v.88, n.1, p.52-58, 2010. 